\title{
Association Between Black Race and Presentation and Liver-Related Outcomes of Patients With Autoimmune Hepatitis
}

\author{
Ynto S. de Boer, ${ }^{,+, a}$ Alessio Gerussi, ${ }^{\S, \|, a}$ Floris F. van den Brand,, \\ Guan-Wee Wong, ${ }^{\ddagger}$ Neil Halliday, ${ }^{\S},{ }^{\oplus}$ Rodrigo Liberal, ${ }^{\ddagger}$ Joost P. H. Drenth," \\ Douglas Thorburn, ${ }^{\S}$ Gerd Bouma, ${ }^{*}$ Dutch Autoimmune Hepatitis Study Group, and \\ Michael A. Heneghan ${ }^{\ddagger}$ \\ ${ }^{*}$ Department of Gastroenterology and Hepatology, Amsterdam University Medical Centers - VU University Medical Center, \\ Amsterdam, the Netherlands; " Institute of Liver Studies, King's College Hospital, Denmark Hill, London, London, United \\ Kingdom; §Sheila Sherlock Liver Centre and UCL Institute for Liver and Digestive Health, Royal Free Hospital, London, United \\ Kingdom; "Department of Medicine, University of Udine, Udine, Italy; "Institute of Immunity and Transplantation, Division of \\ Infection and Immunity, University College London, Royal Free Hospital, London, United Kingdom; and ${ }^{\#}$ Department of \\ Gastroenterology and Hepatology, Radboud University Medical Center, Nijmegen, the Netherlands
}

INTRODUCTION \& AIMS:

METHODS:

RESULTS:

CONCLUSION:
Small studies have found that black patients with autoimmune hepatitis (AIH) present with more aggressive disease. We aimed to characterize the presentation and outcome in black and white patients with AIH.

We performed a retrospective study, collecting information from databases of patients with AIH attending the Institute of Liver studies at King's College Hospital, London (1971-October 2015, the Royal Free Hospital, London (1982 through December 2016) and the multicenter Dutch Autoimmune Hepatitis Study Group cohort (2006-August 2016). We identified 88 black patients with AIH and we compared their clinical characteristics and outcomes to 897 white patients with AIH.

Black patients presented at a younger age (median 38 years vs 45 years) $(P=.007)$, had higher IgG levels (mean $31.0 \mathrm{mg} / \mathrm{dL}$ vs $27.5 \mathrm{mg} / \mathrm{dL})(P=.04)$, but there were no significant differences between groups in auto-antibody profiles, International AIH Group scores, or sex distribution of disease. A higher proportion of black patients had systemic lupus erythematosus $(10 \%)$ than white patients $(2 \%)(P \leq .001)$. There was no significant difference in proportions of patients with a response to standard therapy $(86 \%$ for black patients vs $91 \%$ for white patients; $P=.20)$ or in rate of relapse $(57 \%$ vs $50 \% ; P=.3)$. Despite this, black patients had an increased risk of liver transplantation and liver-related death (hazard ratio 2.4, 95\% confidence interval, $1.4-4.0 ; P<.001$ ). Overall mortality was similar between the two groups.

In a comparison of black and white patients with AIH in Europe, we found that black patients present at a younger age, have higher levels of IgG levels, and a greater proportion have SLE. We also found black patients to have a greater risk of liver transplantation and liver-related mortality, indicating more aggressive disease.

Keywords: IAIHG; SLE; Survival; Disease Progression.

utoimmune hepatitis (AIH) is a rare, chronic

A progressive immune-mediated inflammatory disorder of the liver that affects children and adults. ${ }^{1,2}$ It is characterized by female predominance, hypergammaglobulinemia, circulating autoantibodies and interface hepatitis on liver biopsy. ${ }^{1}$ Clinical presentation ranges from asymptomatic biochemical liver abnormalities to acute liver failure or cirrhosis. ${ }^{1,3,4}$ Genetic factors play a role in the natural history of $\mathrm{AIH}$; white



Abbreviations used in this paper: AlH, autoimmune hepatitis; HCC, hepatocellular carcinoma; IAIHG, International Autoimmune Hepatitis Group; INR, international normalized ratio; IQR, interquartile range; SLE, systemic lupus erythematosus.

Most current article

(C) 2019 by the AGA Institute $1542-3565 / \$ 36.00$

https://doi.org/10.1016/j.cgh.2018.11.028 
$H L A$-DRB ${ }^{*} 0301$ positive AIH type 1 patients are more likely to be male and to deteriorate despite steroids and $H L A-D R B 1 * 0401$ positive patients tend to be older and respond better to corticosteroid therapy. ${ }^{5-7} \mathrm{~A}$ few studies reported differences in disease presentation and outcome between different ethnic groups. ${ }^{8-12}$ In 2 studies from the United States and the United Kingdom, it was found that non-Caucasian patients with AIH have more aggressive disease at initial presentation, a higher likelihood of cirrhosis being present at diagnosis. ${ }^{9,10} \mathrm{~A}$ recent population based analysis found that black AIH patients have a higher rate of hospitalization and death during hospitalization than white patients. ${ }^{13}$ The difference in presentation and outcome between black and patients of other ethnic or racial background may in part be genetically driven, ${ }^{14,15}$ but confounding structural and social factors such as socioeconomic status and access to health care have not convincingly been excluded. The studies to date have been single-center experiences reporting outcomes with relatively small numbers of patients. We aimed to compare the clinical presentation and outcome of black AIH patients from African or Caribbean descent in reference to a Caucasian population in a retrospective multicenter study.

\section{Materials and Methods}

Three well-established and updated databases of patients with AIH attending the Institute of Liver studies at King's College Hospital in London between 1971 and October 2015, the Royal Free Hospital in London between 1982 and December 2016, and the multicenter DAIHG (Dutch Autoimmune Hepatitis Study Group) study cohort between 2006 and August 2016 were reviewed. The King's College Hospital and the Royal Free Hospital are 2 of 7 liver transplant centers in the United Kingdom. These liver units treat local patients, but both have large national and international referral practices. ${ }^{16}$ The DAIHG study cohort data were updated in 6 academic centers, including all 3 Dutch transplant centers, and 10 general referral hospitals. ${ }^{17}$ Patient records were systematically reviewed and examined with regards to self-reported racial background as well as clinical characteristics, excluding patients with features of primary sclerosing cholangitis and primary biliary cholangitis variant syndromes. Black background was based on selfreported sub-Saharan Africa, Afro-American or AfroCaribbean origin, whereas white background was based on self-reported Caucasian or European origin. In the cohort of 985 patients, black race was identified in 88 patients and white race in 897 (Figure 1). All patients had a clinical diagnosis of probable or definite AIH according to the 1999 International Autoimmune Hepatitis Group (IAIHG) scoring system (564 UK and 421 Dutch AIH patients). We compared the black and white patient groups in relation to clinical, laboratory,

\section{What You Need to Know}

\section{Background}

Autoimmune hepatitis (AIH) is a chronic inflammatory condition of the liver that can manifest in all ethnic and racial groups. Genetics, ethnicity, and race have an impact on the development of immune mediated conditions. Socioeconomic status may affect health care outcomes.

\section{Findings}

AIH patients of black background present at an earlier age than white patients. Black AIH patients have a more severe disease course, with a higher chance of liver transplantation or death due to liver failure.

\section{Implications for patient care}

Black AIH patients may need a more stringent therapeutic approach to prevent worse liver-related outcomes.

and histological features as well as treatment outcome, liver transplantation, and overall and liver-related mortality.

As described in previous studies, standard diagnostic criteria for the presence of AIH were fulfilled. ${ }^{17,18}$ All patients were treated according to standardized protocols published previously. ${ }^{19,20}$ Response to treatment and relapse were defined in accordance with the revised IAIHG criteria. ${ }^{21}$ Second-line therapy was defined as ever being treated with medications other than azathioprine or corticosteroids (including mycophenolate mofetil, tacrolimus, cyclosporine A, or sirolimus). The presence of concomitant extra-hepatic autoimmune disease including celiac disease, autoimmune thyroiditis as well as systemic lupus erythematosus (SLE) was retrieved from the patient records. Data on mortality and causes of death were retrieved from medical records or by contacting the attending physicians or general practitioners or family doctors. In the Dutch cohort, liver transplantation rates were assessed by crosschecking the clinical record data with the transplantation list from all 3 transplantation centers. Follow-up ended at the date of death or liver transplantation, or at the end of the study. This study was approved by the Research Ethics Committee of King's College Hospital (04/Q0703/23), the Royal Free Hospital (London, United Kingdom), and the ethics committee at the VU University Medical Center (Amsterdam, the Netherlands) and all the participating centers. In all participating transplant centers, no donor organs were obtained from executed prisoners or other institutionalized persons.

\section{Statistical Analysis}

Statistical analysis was performed with SPSS 22.0 (IBM, Armonk, NY) and GraphPad Prism 7.02 (GraphPad 


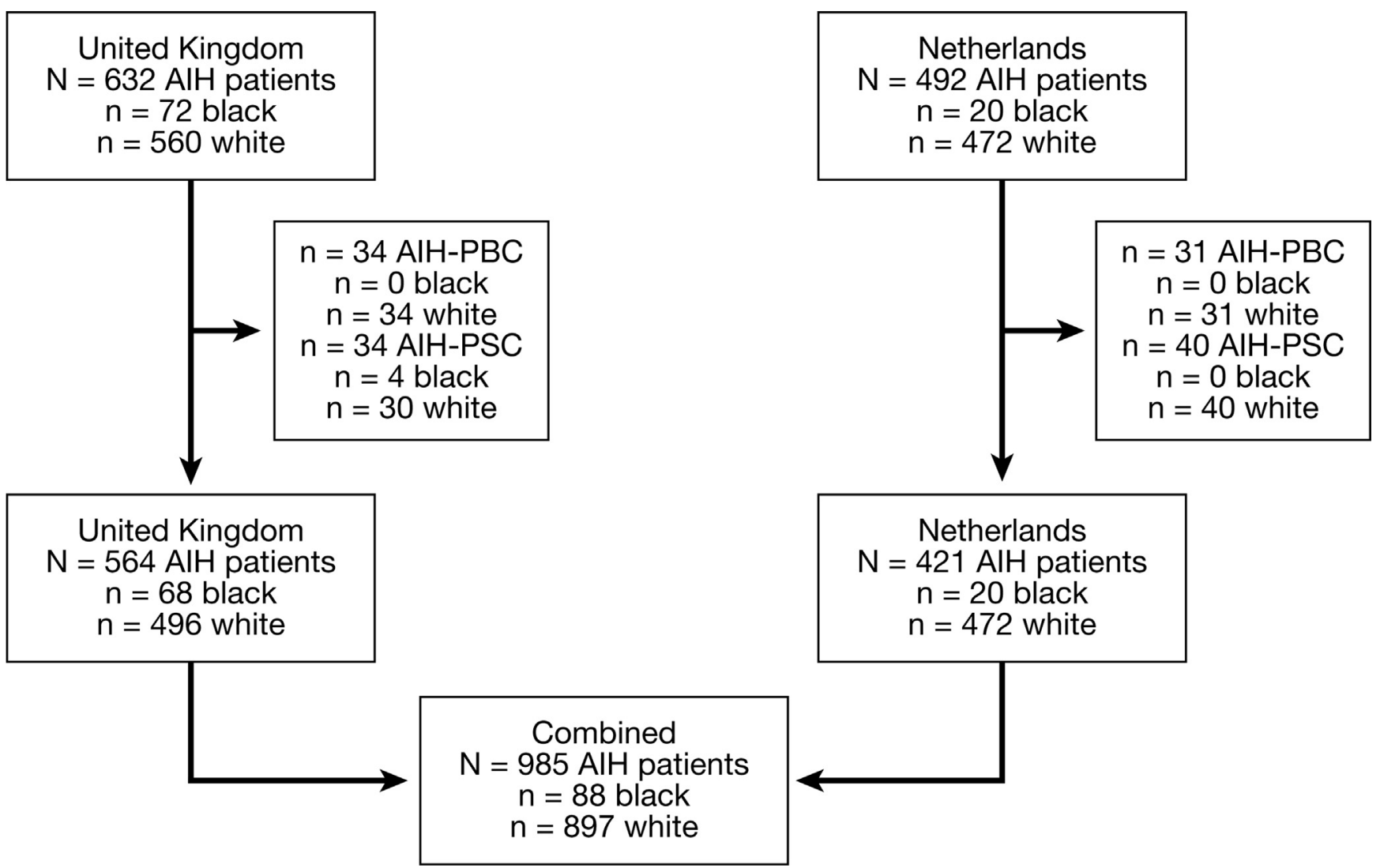

Figure 1. Flowchart of selection of autoimmune hepatitis (AIH) patients in the UK and Dutch cohorts. PBC, primary biliary cholangitis; PSC, primary sclerosing cholangitis.

Software, La Jolla, CA). Demographic and therapy-specific data are given descriptively as mean \pm SD and median (interquartile range [IQR]) when appropriate. Statistical testing of continuous variables between groups was performed with Student's $t$ test, Mann-Whitney $U$ test or Wilcoxon signed rank test. Proportional differences were tested with the chi-square test or Fisher's exact test. A $P$ value of $<.05$ was considered statistically significant. The primary outcome measure was a composite endpoint of liver transplantation and liver-related death. Overall survival curves were obtained via Kaplan-Meier's estimate. For differences in survival between groups the log-rank test and Cox regression analysis was performed, only using time-independent variables.

\section{Results}

\section{UK Cohort}

The UK cohort consisted of $68(12 \%)$ black patients and $496(88 \%)$ white patients. Black patients presented at a younger age (median 38 years of age vs 44 years of age, $P=.05)$, but the proportion of female sex $(77 \%$ vs $79 \%, P=.7$ ), IAIHG score (20 vs $20, P=.15$ ), and transaminase level (median $551 \mathrm{IU} / \mathrm{L}$ vs $586 \mathrm{IU} / \mathrm{L}, P=.9$ ) were similar between both groups. There were no differences in antinuclear antibodies, anti-smooth muscle antibodies, and liver kidney microsome-1 positivity (Supplementary Table 1). Median international normalized ratios (INR) for prothrombin time levels were higher (1.3 vs $1.2, P=.051)$ and albumin levels were lower $(32.1 \mathrm{~g} / \mathrm{L}$ vs $34.4 \mathrm{~g} / \mathrm{L}, P=.017$ ) in black patients. Black patients more often had concomitant SLE $(10 \%$ vs $2 \%, P=.003)$ than white patients, but mean IgG levels were similar (29.3 vs $27.4 \mathrm{~g} / \mathrm{L}, P=.3$ ). The median follow-up and associated treatment exposure was shorter in the black patients than white patients (103 [IQR, 41-149] months vs 126 [IQR, 58-202] months, $P=.01$ ). The response to standard therapy was significantly lower in black patients than white patients ( $81 \%$ vs $93 \%, P=.005)$. Twenty (34\%) black patients and $144(32 \%)$ white patients had cirrhosis at diagnosis $(P=.8)$. Twelve $(18 \%)$ black patients and 38 $(8 \%)$ white patients underwent liver transplantation $(P=$ .007). Sixteen (24\%) black patients and $67(14 \%)$ white patients reached the combined endpoint of livertransplantation and liver-related death $(P=.029)$.

\section{Dutch Cohort}

The Dutch cohort consisted of 20 (5\%) black patients and 401 (95\%) white patients. Black patients presented at a younger age (median 38 years of age vs 46 years of age, $P=.05)$, but the proportion of female sex $(75 \%$ vs 
$77 \%, P=.8$ ), IAIHG score (20 vs $18, P=.3$ ), and transaminase level (median $378 \mathrm{IU} / \mathrm{L}$ vs $492 \mathrm{IU} / \mathrm{L}$, $P=.2$ ) were similar between both groups. There were no differences in antinuclear antibodies, anti-smooth muscle antibodies, and liver kidney microsome-1 positivity (Supplementary Table 2). Median INR (1.1 vs 1.1, $P=.7$ ) and mean albumin $(35.8 \mathrm{~g} / \mathrm{L}$ vs $36.2 \mathrm{~g} / \mathrm{L}, P=.7)$ levels were similar in black and white patients respectively. Black patients more often had concomitant SLE (10\% vs $2 \%, P=.08)$ and had higher mean IgG levels (40.4 vs $27.6 \mathrm{~g} / \mathrm{L}, P=.001)$. Two (13\%) black patients and 56 $(19 \%)$ white patients had cirrhosis at diagnosis $(P=.7)$. The median follow-up and associated treatment exposure were similar in both groups (181 [IQR, 133-212] months vs 178 [IQR, 139-239] months, $P=.7$ ). The response to standard therapy were similar in both groups $(100 \%$ vs $89 \%, P=.1)$. A total of $185(38 \%)$ patients were managed at a transplant center, whereas the majority of patients was treated at general (37\%) or nontransplant academic referral $(25 \%)$ hospitals. Black patients were less often managed at transplant (3 [15\%] vs $155[39 \%], P=.03)$ or academic referral centers $(9$ [45\%] vs 256 [64\%], $P=.09$ ). The rate of biopsy-proven cirrhosis was $19 \%$, which was not related to transplant (21\%) or academic referral center $(21 \%)$. The rates of liver-related death and liver transplantation for all patients were significantly higher in the transplant centers than in the general and academic centers $(n=24$ [15\%] vs $\mathrm{n}=12$ [5\%], $P<.001$ ). No black patients and 11 white patients $(3 \%)$ underwent liver transplantation $(P=1.0)$. Three $(15 \%)$ black patients and $33(8 \%)$ white patients reached the combined endpoint of livertransplantation and liver-related death $(P=.2)$.

\section{Combined Cohort}

The combined study population comprised of 985 patients (736 definite AIH and 259 probable AIH; 88 black patients, 897 white patients). Black patients presented at a younger age than white patients (median 38 years of age vs 45 years of age, $P=.007$ ), but had similar sex distribution and IAIHG post-treatment scores as well as autoantibody positivity (Table 1 ). Black patients had higher IgG levels (mean $31.0 \mathrm{~g} / \mathrm{L}$ vs $27.5 \mathrm{~g} / \mathrm{L}, P=.04$ ) and a higher rate of SLE $(10 \%$ vs $2 \%, P<.001)$. There were no differences in age or severity of presentation between black patients with and without concomitant SLE. The difference in IgG levels between black and white patients persisted after exclusion of patients with SLE $(30.4 \mathrm{~g} / \mathrm{L}$ vs $27.4 \mathrm{~g} / \mathrm{L}, P=.055$. The prevalence of cirrhosis at baseline was similar in both groups $(29 \%$ vs $27 \%, P=.5$ ) in the 822 (84\%) AIH patients who underwent liver biopsy at diagnosis. There was a clear difference in rates of biopsy proven cirrhosis between the UK and Dutch patients ( $32 \%$ vs $19 \%, P<.001)$. The INRs were similar in black and white patients, whereas

Table 1. Baseline Characteristics

\begin{tabular}{|c|c|c|c|c|}
\hline & Black $(\mathrm{n}=88)$ & White $(\mathrm{n}=897)$ & $P$ & $\mathrm{n}$ \\
\hline Age at diagnosis, y & $38(23-49)$ & $45(24-58)$ & .007 & 981 \\
\hline Female & $67(76)$ & $700(78)$ & .7 & 985 \\
\hline Post-treatment IAIHG score & $20(17-22)$ & $19(17-22)$ & .9 & 941 \\
\hline Definite post-treatment IAIHG score & $61(69)$ & $665(74)$ & .3 & 985 \\
\hline ALT or AST, IU/L & $483(192-932)$ & 539 (197-1080) & .8 & 850 \\
\hline ALP, IU/L & $191(145-269)$ & $174(129-252)$ & .1 & 823 \\
\hline Bilirubin, $\mathrm{mmol} / \mathrm{L}$ & $57(30-165)$ & $55(19-180)$ & .7 & 810 \\
\hline Creatinine, $\mu \mathrm{mol} / \mathrm{L}$ & $72(62-89)$ & $73(63-85)$ & .9 & 597 \\
\hline INR & $1.2(1.1-1.6)$ & $1.2(1.0-1.4)$ & .082 & 634 \\
\hline Mean albumin, g/L (range) & $32.8(16-46)$ & $35.1(15-55)$ & .005 & 762 \\
\hline Mean peak IgG, g/L (range) & $31.0(4.6-91.1)$ & $27.5(4.8-89.5)$ & .043 & 748 \\
\hline ANA positivity $\geq 1: 40$ & $58(68)$ & $572(69)$ & .8 & 909 \\
\hline SMA positivity $\geq 1: 40$ & $47(55)$ & $478(60)$ & .4 & 890 \\
\hline LKM-1 positivity $\geq 1: 40$ & $4(5)$ & $44(6)$ & .8 & 807 \\
\hline AMA positivity $\geq 1: 80$ & $2(2)$ & $30(4)$ & .8 & 924 \\
\hline SLE & $9(10)$ & $19(2)$ & $<.001$ & 985 \\
\hline Thyroid disease & $8(9)$ & $127(14)$ & .2 & 983 \\
\hline Hypothyroidism & $7(10)$ & $93(11)$ & & \\
\hline Hyperthyroidism & $1(2)$ & $28(3)$ & & \\
\hline Celiac disease & $0(0)$ & $8(1)$ & 1.0 & 983 \\
\hline Acute presentation ( $<6$ months) & $54(68)$ & $375(61)$ & .3 & 693 \\
\hline Cirrhosis at diagnosis & $22(29)$ & $200(27)$ & .6 & 822 \\
\hline Managed at transplant center & $71(81)$ & $651(73)$ & .1 & 985 \\
\hline
\end{tabular}

NOTE. Values are median (interquartile range) or $\mathrm{n}(\%)$, unless otherwise indicated.

ALT, alanine aminotransferase; ALP, alkaline phosphatase; AMA, antimitochondrial antibody; ANA, antinuclear antibodies; AST, aspartate aminotransferase; IAIHG, International Autoimmune Hepatitis Group; LKM-1, liver kidney microsome-1 antibody; SLE, systemic lupus erythematosus; SMA, anti-smooth muscle antibody. 
Table 2. Therapy and Outcome

\begin{tabular}{lcccc}
\hline & $\begin{array}{c}\text { Black } \\
(\mathrm{n}=88)\end{array}$ & $\begin{array}{c}\text { White } \\
(\mathrm{n}=897)\end{array}$ & $P$ & $\mathrm{n}$ \\
\hline Therapy & & & & \\
Steroids for induction & $84(99)$ & $841(95)$ & .2 & 971 \\
Azathioprine for maintenance & $59(75)$ & $703(81)$ & .2 & 949 \\
Ever on second-line therapy & $13(17)$ & $96(11)$ & .1 & 953 \\
Response to standard therapy & $67(86)$ & $773(91)$ & .1 & 928 \\
Relapse & $39(57)$ & $405(50)$ & .3 & 875 \\
Number of relapses & $1(0-3)$ & $1(0-2)$ & .018 & 815 \\
Outcome & & & & \\
HCC & $2(2)$ & $23(3)$ & 1.0 & 973 \\
Liver transplantation & $12(14)$ & $49(6)$ & .002 & 984 \\
Liver transplantation + & $19(22)$ & $100(11)$ & .004 & 985 \\
$\quad$ liver-related death & $10(11)$ & $138(15)$ & .3 & 985 \\
Overall death & & & & \\
\hline
\end{tabular}

NOTE. Values are $\mathrm{n}(\%)$ or median (interquartile range).

$\mathrm{HCC}$, hepatocellular carcinoma.

the albumin levels were significantly lower (mean 32.8 $\mathrm{g} / \mathrm{L}$ vs $35.1 \mathrm{~g} / \mathrm{L}, P=.005$ ) in black patients. Both black and white patients were treated with steroids as standard induction therapy (99\% vs $95 \%, P=.2)$ and had a similar exposure to azathioprine as maintenance therapy (75\% vs $81 \%, P=.2$ ) (Table 2). Black patients had a similar clinical response rates to standard therapy compared with white patients ( $86 \%$ vs $91 \%, P=.2$ ) and also comparable occurrence of at least 1 relapse (57\% vs $50 \%, P=.3$ ). However, during follow-up there was a higher proportion total number of recorded relapses in black AIH patients in both the King's College Hospital and the Dutch cohorts $(P=.018)$. Overall, there was no significant difference in the rate of use of second-line therapies $(17 \%$ vs $11 \%, P=.1)$.

\section{Outcome}

The median duration of follow-up in the combined cohort was shorter in the black than in the white patients (127 [IQRm 48-173] months vs 152 [IQR, 91-223] months, $P<.001$ ). The rate of hepatocellular carcinoma (HCC) development was similar in both groups $(2 \%$ vs $2 \%, P=1.0$ ), but the incidence per 10 patient years was lower in the white patient group $(0.018$ per 10 patientyears vs 0.022 per 10 patient-years). The rate of transplantation and liver-related death was significantly
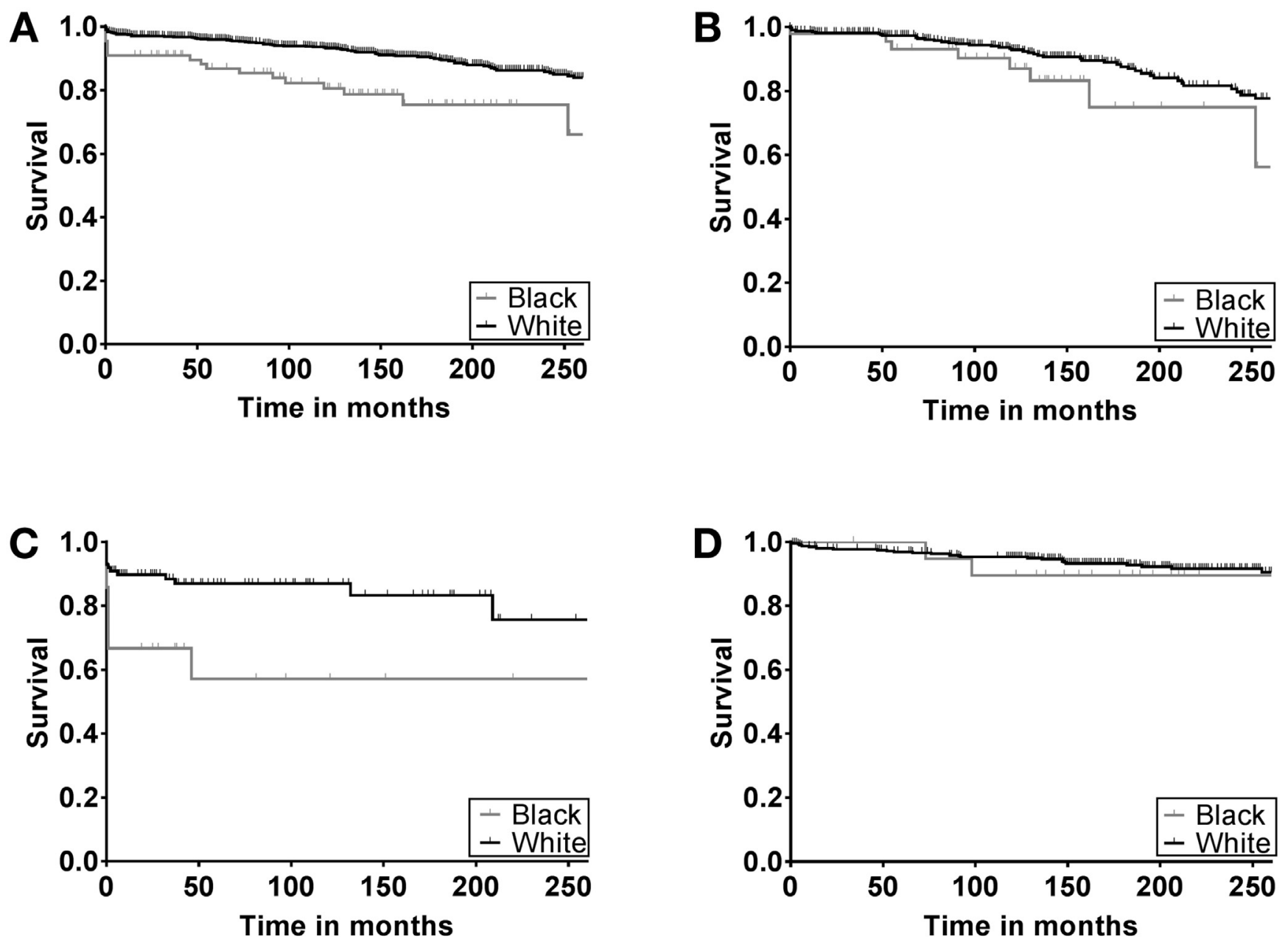

Figure 2. Transplant free and liver related death survival analysis in the $(A)$ combined, $(B)$ Kings College Hospital (United Kingdom), (C) Royal Free Hospital (United Kingdom), and (D) Dutch cohorts. 
higher in the black patients in the UK cohort $(P=.029)$, whereas the rates of transplantation, liver-related mortality, and overall mortality did not differ significantly between black and white patients in the Dutch cohort. In the combined cohort, the black AIH patients underwent liver transplantation more often than white patients (14\% vs $6 \%, P=.002)$, but overall mortality was similar between the 2 groups (11\% vs $15 \%, P=.3)$. Log-rank survival analysis showed an impaired combined transplant-free and liver-related mortality for black patients in the combined UK and Dutch cohorts $(P<.001)$ (Figure 2A). This was primarily driven by the UK cohort $(P<.001$, Figure $2 B$ and $C)$, as the Dutch cohort did not reveal a significant association $(P=.4)$ (Figure $2 D$ ). This suggest that the difference in rates of cirrhosis between the UK and Dutch patients ( $32 \%$ vs $19 \%, P<.001$ ) is in part driving this association. Cox regression analysis in the combined UK and Dutch cohorts showed an association of black race with liver transplant and liver-related death (hazard ratio, 2.4; 95\% confidence interval, 1.4-4.0; $P=.001$ ) (Table 3), independent of age, cirrhosis at diagnosis, and SLE in the multivariate analysis. Incorporation of transplant center status and country in the model did not change these results. The presence of cirrhosis at diagnosis was associated with an increased risk of liver transplantation or liver-related death.

\section{Discussion}

In this retrospective study of black patients with AIH from selected centers in the United Kingdom and the Netherlands, we observed a lower age of onset and a greater risk of liver transplant or liver-related death, which may illustrate a more aggressive disease course compared with white patients. We also demonstrated that these outcomes occurred in health care systems with universal access to care, even without a higher likelihood of cirrhosis at diagnosis or without an initial inferior apparent treatment responses to induction therapy among black patients. Higher IgG levels at diagnosis were noted compared with a white reference population. Although no differences in terms of autoantibody profile were noted, black patients more often had concomitant SLE. Overall, there was a low rate of HCC and we did not observe an association between HCC development and race which is consistent with the similar rates of cirrhosis in both groups. ${ }^{22}$ In both countries and health care systems, the vast majority of patients received corticosteroids for induction of remission, with azathioprine being added for maintenance therapy. Interestingly, there were no differences in terms of response of therapy between groups, and a similar proportion of patients needed escalation of therapy with second line agents. However, the number of relapses was higher in black patients compared with white patients, suggesting that these patients have a more severe disease phenotype and are in need of a better maintenance therapy. Alternatively, limited compliance to therapy could be factor, although we could not reliably address this issue. Lim et $\mathrm{al}^{8}$ reported that although both black and white patients responded well to standard therapy, the dosage of steroids was significantly higher in black patients despite similar use of azathioprine (Table 4). These data suggest that current treatment regimens may be inadequate for black patients; therefore, future studies should focus on the development of different treatment protocols stratified according to race to address this issue. ${ }^{23,24}$ Importantly, this study also confirms that race also impacts on the natural history of the disease, as black patients were more likely to have progressive disease requiring liver transplantation. We propose 3 possible explanations for this outcome. First, and although this was a multicenter study, it was hospital based and therefore could be limited by tertiary referral bias, which might lead to an overestimation in severity. In line with this, we observed overall less severe disease with lower rates of cirrhosis and outcomes in the Dutch cohort, which comprised AIH patients managed predominantly at general and academic hospitals, and less frequently at transplant hospitals, whereas the UK cohort consisted of 2 transplant centers. Nevertheless, as advanced health care is accessible through both the National Health Service in

Table 3. Survival: Transplant and Liver-Related Death

\begin{tabular}{|c|c|c|c|c|c|c|c|c|}
\hline & \multicolumn{4}{|c|}{ Univariate } & \multicolumn{4}{|c|}{ Overall } \\
\hline & \multicolumn{2}{|c|}{ UK Cohort } & \multicolumn{2}{|c|}{ Dutch Cohort } & \multicolumn{2}{|c|}{ Univariate } & \multicolumn{2}{|c|}{ Multivariate } \\
\hline & HR (95\% Cl) & $P$ & HR $(95 \% \mathrm{Cl})$ & $P$ & $\mathrm{HR}(95 \% \mathrm{Cl})$ & $P$ & $\mathrm{HR}(95 \% \mathrm{Cl})$ & $P$ \\
\hline Black & $2.5(1.5-4.4)$ & .001 & $1.6(0.5-5.4)$ & .4 & $2.5(1.6-4.2)$ & $<.001$ & $2.4(1.4-4.0)$ & .001 \\
\hline Age & $1.0(1.0-1.0)$ & .6 & $1.0(1.0-1.0)$ & .012 & $1.0(1.0-1.0)$ & .14 & $1.0(1.0-1.0)$ & .049 \\
\hline Gender & $0.9(0.5-1.5)$ & .7 & $1.2(0.5-2.7)$ & .7 & $0.9(0.6-1.5)$ & .9 & & \\
\hline Cirrhosis at diagnosis & $3.3(2.1-5.1)$ & $<.001$ & $1.8(0.9-3.9)$ & .12 & $3.2(2.2-4.5)$ & $<.001$ & $3.1(2.1-4.4)$ & $<.001$ \\
\hline SLE & 2.7 (1.2-6.2) & .02 & $1.0(0.1-7.8)$ & .9 & $2.3(1.1-4.9)$ & .035 & $1.9(0.9-4.3)$ & .12 \\
\hline
\end{tabular}

NOTE. Cox regression analysis of combined liver transplant and/or liver related death. Patients without biopsy at diagnosis were included in this analysis as not having cirrhosis. The multivariate analysis was conducted in 969 of 985 (98\%) patients with available data for included variables.

$\mathrm{Cl}$, confidence interval; HR, hazard ratio; SLE, systemic lupus erythematosus. 
Table 4. Review of Literature on Ethnic/Racial Background and Presentation and Outcome in Autoimmune Hepatitis

\begin{tabular}{|c|c|c|c|c|c|}
\hline Study & Population & Presentation & Response & Outcome & Study setting \\
\hline Lim et al $(2001)^{8}$ & $\begin{array}{l}27 \text { African American and } 24 \\
\text { white AlH patients }\end{array}$ & $\begin{array}{l}\text { Cirrhosis in } 85 \% \text { of African } \\
\text { Americans and } 38 \% \text { of } \\
\text { white patients }\end{array}$ & $\begin{array}{l}\text { Both groups responded well to } \\
\text { therapy }\end{array}$ & $\begin{array}{l}\text { African Americans required } \\
\text { higher prednisone doses } \\
\text { than white patients }\end{array}$ & 1 tertiary referral center \\
\hline Zolfino et al $(2002)^{9}$ & $\begin{array}{l}6 \text { African and } 5 \text { Asian and } 1 \\
\text { Arabic AlH patients }\end{array}$ & $\begin{array}{l}\text { Cirrhosis in } 1 \text { of the African } \\
\text { and } 4 \text { Asian patients }\end{array}$ & $\begin{array}{l}\text { Complete response in } 2 \\
\text { African, } 2 \text { Asian, and } 1 \\
\text { Arab patient; partial or no } \\
\text { response in } 7 \text { patients }\end{array}$ & $\begin{array}{l}\text { Death or transplantation in } 2 \\
(33 \%) \text { African, } 4(80 \%) \\
\text { Asian, and } 1(100 \%) \text { Arab } \\
\text { patient }\end{array}$ & 1 tertiary referral center \\
\hline Verma et al $(2007)^{10}$ & $\begin{array}{l}37 \text { Black and } 64 \text { non-black AlH } \\
\text { patients }\end{array}$ & $\begin{array}{l}\text { Cirrhosis and acute } \\
\text { presentation were more } \\
\text { common in black than } \\
\text { non-black patients } \\
\text { ( } 57 \% \text { vs } 38 \% \text { and } 76 \% \\
\text { vs } 50 \% \text {, respectively) }\end{array}$ & $\begin{array}{l}\text { Black patients were less likely } \\
\text { to achieve remission }(76 \%) \\
\text { than non-black patients } \\
(90 \%)\end{array}$ & $\begin{array}{l}\text { Black patients had a } 4 \text {-fold } \\
\text { higher mortality rate and } \\
\text { were referred } 2 \text { times more } \\
\text { often for transplantation } \\
\text { than non-black patients }\end{array}$ & 1 tertiary referral center \\
\hline Wen et al (2018) & $\begin{array}{l}\text { Hospitalizations for AlH in } 1463 \\
\text { black and } 4666 \text { white AlH } \\
\text { patients }\end{array}$ & $\begin{array}{l}\text { Cirrhosis in } 12.5 \% \text { of black } \\
\text { and } 15.1 \% \text { of white } \\
\text { patients }\end{array}$ & $\begin{array}{l}\text { Black patients were } \\
\text { hospitalized for } \mathrm{AlH} \text { at a } \\
\text { rate } 69 \% \text { higher than } \\
\text { whites }\end{array}$ & $\begin{array}{l}\text { Black patients had higher odds } \\
\text { of death during } \\
\text { hospitalization for AlH than } \\
\text { white patients }\end{array}$ & $\begin{array}{l}\text { U.S. Nationwide Inpatient } \\
\text { Sample database } \\
(2008-2012)\end{array}$ \\
\hline Webb et al $(2018)^{16}$ & $\begin{array}{l}\text { Transplantation list: } 796 \text { black } \\
\text { and } 3665 \text { white AlH patients }\end{array}$ & - & - & $\begin{array}{l}\text { Black patients with AlH were } \\
\text { listed for transplantation } \\
\text { more than } 10 \text { years younger } \\
\text { than white patients }\end{array}$ & $\begin{array}{l}\text { U.S. and UK } \\
\text { transplantation } \\
\text { centers (1995-2014) }\end{array}$ \\
\hline Lee et al $(2018)^{12}$ & $\begin{array}{l}10 \text { Black, } 29 \text { Latino, and } 19 \\
\text { Asian Pacific Islander AlH } \\
\text { and } 2049 \text { control patients }\end{array}$ & $\begin{array}{l}\text { Biochemistry and rates of } \\
\text { cirrhosis were similar } \\
\text { between the groups }\end{array}$ & $\begin{array}{l}\text { No difference in time to steroid } \\
\text { discontinuation or clinical } \\
\text { course between the groups }\end{array}$ & $\begin{array}{l}\text { Black, Latino and Asian Pacific } \\
\text { Islander patients had almost } \\
10 \text { times higher odds of AlH } \\
\text { than whites }\end{array}$ & 1 tertiary referral center \\
\hline
\end{tabular}

AlH, autoimmune hepatitis. 
the United Kingdom and mandatory insurance policy in the Netherlands, this bias likely affects both groups. Hence, it seems unlikely to account for the poorer outcome observed in black AIH patients, although the relatively small number of included black AIH patients in the Dutch cohort may explain the lack of association with outcome in the Dutch cohort due to lack of power. A recent study of the UK and U.S. national liver transplant registries reported that black patients were listed at younger age and had higher Model for End-Stage Liver Disease scores than other races (Table 4). ${ }^{25}$ Second, socioeconomic status, health care access, and practice, and thus quality of care, are factors that must be considered comparing disease characteristics and outcomes among different groups. ${ }^{26}$ For example, mortality differences between white and African descendent North Americans with cirrhosis disappear after adjustment for socioeconomic status. ${ }^{27}$ The earlier age at diagnosis and similar cirrhosis rates argue against a systematic delay in the diagnosis of AIH in black patients, assuming that untreated disease progression rates are similar. The elevated hazard of liver transplantation or liver-related death for black patients could be attributed to a more aggressive disease phenotype, which might progress despite similar rates of initial treatment response, which is supported by a recent population study in the United States (Table 4). ${ }^{13}$ Unfortunately, Wen et $\mathrm{al}^{13}$ did not report on the clinical characteristics, but rather relied on international classification of disease 9 codes. Conversely, the differences in liver-related mortality and liver transplantation could reflect variations in the quality and experience of care depending upon race. Last, it is possible that genetic variations may have been responsible for the worse outcome observed in black patients with AIH. There are well established differences between black and white patient groups regarding the incidence of SLE and other immunoinflammatory disorders such as sarcoidosis. Additionally, differences in other immune parameters such as ethnic neutropenia ${ }^{28}$ and the distribution of the Duffy antigen receptor for chemokines polymorphisms ${ }^{29}$ suggest that genetic influences on the immune system differ between populations. Previous studies have shown that genetic factors influence AIH occurrence, clinical expression, and response to corticosteroid therapy, ${ }^{6,14,30}$ but the genetic contributions to disease onset and phenotype of $\mathrm{AIH}$ have not been explored in patients of African or Caribbean descent. In white Northern European populations, the $H L A-D R B 1^{*} 04: 01$ genotype was associated with a higher rate of remission and with a lower frequency of cirrhosis and need for liver transplantation. ${ }^{5}$ Interestingly, it has been shown that HLA-DR4 is underrepresented in African Americans compared with Caucasian individuals. ${ }^{31}$ The current study provides no information about HLA class II genotypes, constituting 1 key limitation in interpreting the data. Additionally, common with other retrospective studies, our results may be influenced by referral bias, missing data, skewed outcome parameters and we cannot ascribe causality of poorer outcomes to race. As race was self-reported and categorized as black or white, we could not control for the likely genetic heterogeneity within these large groups. A further limitation is the lack of data on adherence to treatment within the studied groups. However, the strength of this study comprises the large catchment area in 2 different countries with accessible health care systems.

Future, prospective studies are required to explore the mechanism, importance, and generalizability of our findings. The impact of genetic variants among different racial groups in Europe, and globally, on clinical outcomes would help inform our understanding of disease biology, etiology, and risk prediction. Qualitative and quantitative exploration of the experiences of patients and access to health care, capturing data on, among others, socioeconomic status, race, sex, and treatment center should be performed. The proposed IAIHG retrospective and prospective registries offer a suitable starting point and further focused studies will be required. ${ }^{23,24}$

In summary, the results of this study show that the presentation and clinical course of AIH is different in black patients compared with a reference cohort of white AIH patients. Black AIH patients present at a younger age, with higher IgG levels and a higher prevalence of SLE than a white reference population. Black AIH patients appear to have a higher rate of transplantation and liver-related mortality, despite a similar disease stage at presentation. It is likely that a combination of different factors may account for this observation, including time of diagnosis, treatment regimen, and genetic and environmental disparities between the different groups.

\section{Supplementary Material}

Note: To access the supplementary material accompanying this article, visit the online version of Clinical Gastroenterology and Hepatology at www.cghjournal.org, and at https://doi.org/10.1016/j.cgh.2018.11.028

\section{References}

1. Liberal R, Krawitt EL, Vierling JM, et al. Cutting edge issues in autoimmune hepatitis. J Autoimmun 2016;75:6-19.

2. Heneghan MA, Yeoman AD, Verma S, et al. Autoimmune hepatitis. Lancet 2013;382:1433-1444.

3. Feld JJ, Dinh H, Arenovich T, et al. Autoimmune hepatitis: effect of symptoms and cirrhosis on natural history and outcome. Hepatology 2005;42:53-62.

4. Roberts SK, Therneau TM, Czaja AJ. Prognosis of histological cirrhosis in type 1 autoimmune hepatitis. Gastroenterology 1996;110:848-857.

5. Kirstein MM, Metzler F, Geiger E, et al. Prediction of short- and long-term outcome in patients with autoimmune hepatitis. Hepatology 2015;62:1524-1535.

6. van Gerven NM, de Boer YS, Zwiers A, et al. HLA-DRB1*03:01 and HLA-DRB1*04:01 modify the presentation and outcome in autoimmune hepatitis type-1. Genes Immun 2015;16:247-252. 
7. Mieli-Vergani G, Heller S, Jara P, et al. Autoimmune hepatitis. J Pediatr Gastroenterol Nutr 2009;49:158-164.

8. Lim KN, Casanova RL, Boyer TD, et al. Autoimmune hepatitis in African Americans: presenting features and response to therapy. Am J Gastroenterol 2001;96:3390-3394.

9. Zolfino $\mathrm{T}$, Heneghan MA, Norris $\mathrm{S}$, et al. Characteristics of autoimmune hepatitis in patients who are not of European Caucasoid ethnic origin. Gut 2002;50:713-717.

10. Verma S, Torbenson M, Thuluvath PJ. The impact of ethnicity on the natural history of autoimmune hepatitis. Hepatology 2007; 46:1828-1835.

11. Wong RJ, Gish R, Frederick T, et al. The impact of race/ethnicity on the clinical epidemiology of autoimmune hepatitis. J Clin Gastroenterol 2012;46:155-161.

12. Lee B, Holt EW, Wong RJ, et al. Race/ethnicity is an independent risk factor for autoimmune hepatitis among the San Francisco underserved. Autoimmunity 2018;51:258-264.

13. Wen JW, Kohn MA, Wong R, et al. Hospitalizations for Autoimmune Hepatitis Disproportionately Affect Black and Latino Americans. Am J Gastroenterol 2018;113:243-253.

14. de Boer YS, van Gerven NM, Zwiers A, et al. Genome-wide association study identifies variants associated with autoimmune hepatitis type 1. Gastroenterology 2014;147:443-452.e5.

15. Oliveira LC, Porta G, Marin ML, et al. Autoimmune hepatitis, HLA and extended haplotypes. Autoimmun Rev 2011;10:189-193.

16. Webb GJ, Hodson J, Chauhan A, et al. Proximity to transplant center and outcome among liver transplant patients. Am J Transplant 2019;19:208-220.

17. van Gerven NM, Verwer BJ, Witte BI, et al. Epidemiology and clinical characteristics of autoimmune hepatitis in the Netherlands. Scand J Gastroenterol 2014;49:1245-1254.

18. Wong GW, Yeong T, Lawrence D, et al. Concurrent extrahepatic autoimmunity in autoimmune hepatitis: implications for diagnosis, clinical course and long-term outcomes. Liver Int 2017; 37:449-457.

19. European Association for the Study of the Liver. EASL Clinical Practice Guidelines: Autoimmune hepatitis. J Hepatol 2015; 63:971-1004.

20. Manns MP, Czaja AJ, Gorham JD, et al. Diagnosis and management of autoimmune hepatitis. Hepatology 2010; 51:2193-2213.

21. Alvarez F, Berg PA, Bianchi FB, et al. International Autoimmune Hepatitis Group Report: review of criteria for diagnosis of autoimmune hepatitis. J Hepatol 1999;31:929-938.
22. Yeoman AD, Al-Chalabi T, Karani JB, et al. Evaluation of risk factors in the development of hepatocellular carcinoma in autoimmune hepatitis: Implications for follow-up and screening. Hepatology 2008;48:863-870.

23. Liberal R, de Boer YS, Andrade RJ, et al. Expert clinical management of autoimmune hepatitis in the real world. Aliment Pharmacol Ther 2017;45:723-732.

24. de Boer YS, Liberal R, Vergani D, et al. Real-world management of juvenile autoimmune liver disease. United European Gastroenterol J 2018;6:1032-1038.

25. Webb GJ, Rana A, Hodson J, et al. Twenty-Year Comparative Analysis of Patients With Autoimmune Liver Diseases on Transplant Waitlists. Clin Gastroenterol Hepatol 2018;16:278-287.e7.

26. Czaja AJ. Autoimmune hepatitis in special patient populations. Best Pract Res Clin Gastroenterol 2011;25:689-700.

27. Nguyen GC, Thuluvath PJ. Racial disparity in liver disease: Biological, cultural, or socioeconomic factors. Hepatology 2008; 47:1058-1066.

28. Denic S, Narchi H, Al Mekaini LA, et al. Prevalence of neutropenia in children by nationality. BMC Hematol 2016;16:15.

29. Graham GJ, Locati M, Mantovani A, et al. The biochemistry and biology of the atypical chemokine receptors. Immunol Lett 2012; 145:30-38.

30. Doherty DG, Donaldson PT, Underhill JA, et al. Allelic sequence variation in the HLA class II genes and proteins in patients with autoimmune hepatitis. Hepatology 1994;19:609-615.

31. Reveille JD, Moulds JM, Ahn C, et al. Systemic lupus erythematosus in three ethnic groups: I. The effects of HLA class II, C4, and CR1 alleles, socioeconomic factors, and ethnicity at disease onset. LUMINA Study Group. Lupus in minority populations, nature versus nurture. Arthritis Rheum 1998;41:1161-1172.

Reprint requests

Address requests for reprints to: Michael A. Heneghan, MD, Institute of Liver Studies, King's College Hospital, Denmark Hill, London SE5 9RS, United Kingdom. e-mail: michael.heneghan@nhs.net; fax: +44 (0) 2032993167.

\section{Acknowledgments}

Dutch Autoimmune Hepatitis Study Group collaborators: N.M. van Gerven, U. Beuers, K.J. van Erpecum, H.R. van Buuren, J.W. den Ouden, J.T. Brouwer, J.M. Vrolijk, R.C. Verdonk, B. van Hoek, G.H. Koek, M.M.J. Guichelaar, E. Bloemena, C.M.J. van Nieuwkerk, T.C.M.A. Schreuder, E.J. van der Wouden, J.J.M. van Meyel, L.C. Baak, P.H.G.M. Stadhouders, M. Klemt-Kropp, M.A.M.T. Verhagen, A. Bhalla, J.Ph. Kuijvenhoven.

\section{Conflicts of interest}

The authors disclose no conflicts. 
Supplementary Table 1. Baseline Characteristics, Therapy, and Outcome of UK AlH Patients

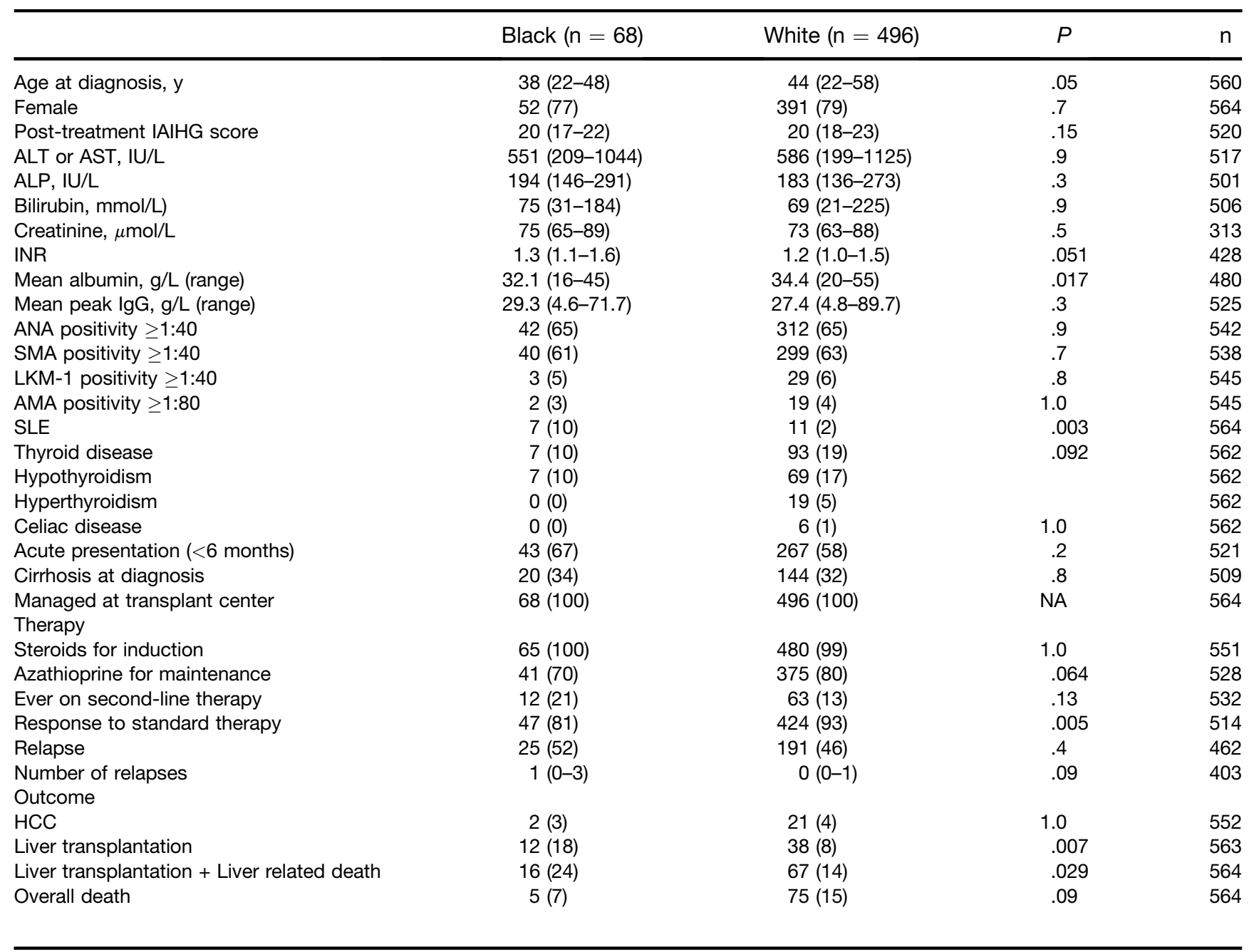

NOTE. Values are median (interquartile range) or $\mathrm{n}(\%)$, unless otherwise indicated.

$\mathrm{AlH}$, autoimmune hepatitis; ALT, alanine aminotransferase; ALP, alkaline phosphatase; AMA, antimitochondrial antibody; ANA, antinuclear antibody; AST, aspartate aminotransferase; HCC, hepatocellular carcinoma; IAIHG, International Autoimmune Hepatitis Group; LKM-1, liver kidney microsome-1 antibody; SLE, systemic lupus erythematosus; SMA, anti-smooth muscle antibody. 
Supplementary Table 2. Baseline Characteristics, Therapy, and Outcome in the Dutch Cohort

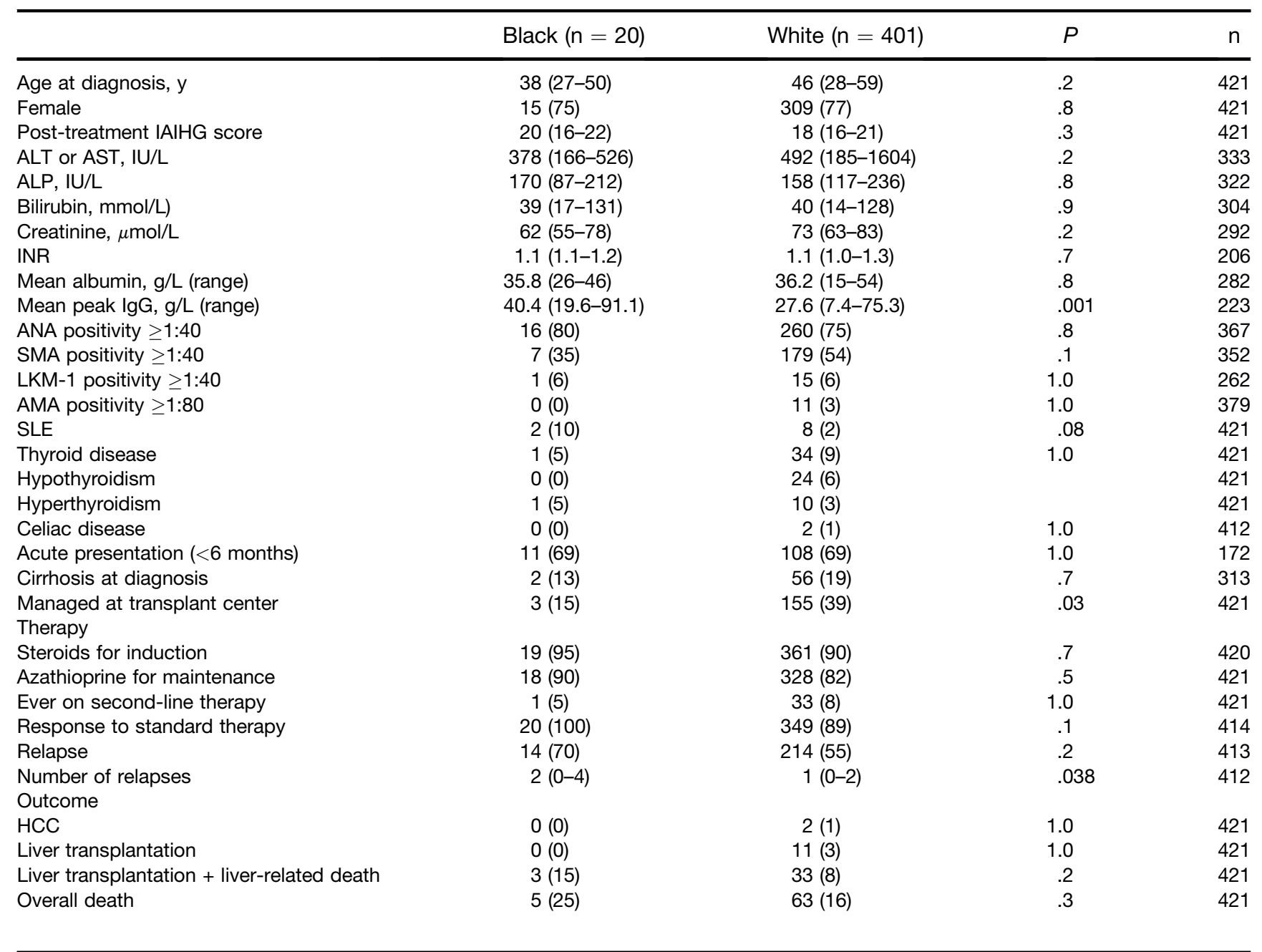

NOTE. Values are median (interquartile range) or $\mathrm{n}(\%)$, unless otherwise indicated.

ALT, alanine aminotransferase; ALP, alkaline phosphatase; AMA, antimitochondrial antibody; ANA, antinuclear antibody; AST, aspartate aminotransferase; HCC hepatocellular carcinoma; IAlHG, International Autoimmune Hepatitis Group; LKM-1, liver kidney microsome-1 antibody; SLE, systemic lupus erythematosus; SMA, anti-smooth muscle antibody. 